\title{
Synthesis and Electrochemical Characterization of Palladium Crystals Enclosed by (100) Facets by Seed-Mediated Fabrication
}

\author{
Eiji Higuchi (iD, Masashi Kawai, Masanobu Chiku, and Hiroshi Inoue \\ Department of Applied Chemistry, Graduate School of Engineering, Osaka Prefecture University, Sakai, Osaka 599-8531, Japan \\ Correspondence should be addressed to Eiji Higuchi; e-higuchi@chem.osakafu-u.ac.jp
}

Received 17 October 2017; Revised 15 December 2017; Accepted 25 December 2017; Published 21 January 2018

Academic Editor: Adalgisa Rodrigues de Andrade

Copyright (C) 2018 Eiji Higuchi et al. This is an open access article distributed under the Creative Commons Attribution License, which permits unrestricted use, distribution, and reproduction in any medium, provided the original work is properly cited.

\begin{abstract}
Pd crystals enclosed by (100) facets were prepared in an aqueous solution containing cetyltrimethylammonium bromide (CTAB) as the capping agent and ascorbic acid as the reducing agent at 30,40 , and $50^{\circ} \mathrm{C}$ by a modified seed-mediated fabrication technique. Regardless of the reaction temperature, the absorption peak between 300 and $400 \mathrm{~nm}$ assigned to $\mathrm{PdCl}_{4}{ }^{2-}$ decreased with an increase in the reaction time after the addition of ascorbic acid in the $\mathrm{PdCl}_{4}{ }^{2-}$ aqueous solution containing CTAB because of Pd deposition. The field emission-scanning electron microscopy images showed that the Pd crystals were enclosed by only (100) facets, and their fractions depended on the reaction temperature. The ratios of the peak current at 0.54 and $0.48 \mathrm{~V}$ were $0.60,0.54$, and 0.47 for the samples prepared at 30,40 , and $50^{\circ} \mathrm{C}$, respectively, suggesting that the proportion of the (100) facet on the Pd surface was higher at lower temperatures.
\end{abstract}

\section{Introduction}

Polymer electrolyte fuel cells (PEFCs) that use hydrogen as fuel are attracting considerable attention as primary power sources for electric vehicles owing to their high energy conversion efficiency and low emission of pollutants. Ptbased electrocatalysts with high catalytic activity for oxygen reduction reaction (ORR) have been used as cathode catalysts in PEFCs. Pd-based catalysts have also been used for ORR, because Pd is cheaper and more abundant than Pt. The electrocatalytic activity per unit real surface area (specific activity) for ORR on Pd single crystals has been reported to increase in the order of $\operatorname{Pd}(110)<\operatorname{Pd}(111) \ll \operatorname{Pd}(100)$, which is reverse to that for ORR on Pt single crystals [1]. Moreover, $\mathrm{Pd}(100)$ shows higher ORR activity than $\mathrm{Pt}(110)$, suggesting that the $\operatorname{Pd}(100)$ surface is the most active surface for ORR. Therefore, Pd nanoparticles consisting of only the (100) surface will exhibit a high ORR activity. This necessitates control of structure or shape during the preparation of Pd nanoparticles. Chemical metal deposition methods employing capping agents that preferentially adsorb on a specific facet to suppress crystal growth are often used for this purpose. Recently, many studies on the preparation of shape-controlled nanoparticles have been reported [2-9].
Pd nanocubes and nanobars enclosed by (100) facets were successfully produced with a yield of $80 \%$ by solvothermal synthesis at $150^{\circ} \mathrm{C}$ for $8 \mathrm{~h}$ using N,N-dimethylformamide as the reducing agent, palladium(II) acetylacetonate as the $\mathrm{Pd}$ precursor, and sodium iodide as the capping agent [2].

Seed-mediated growth is another efficient and versatile method to synthesize metal crystals with controlled sizes and shapes. This method is particularly advantageous because it can be used to synthesize metal crystals with controlled shapes by choosing suitable seed nanoparticles and manipulating the crystal growth conditions. The seedmediated growth method normally consists of two processes: synthesis of seed crystals and their shape-controlled growth in a growth solution containing a metal precursor, reducing agent, and capping reagent. The size of the resultant metal crystal is determined by that of the seed crystal, while its shape is mainly controlled by the difference in the growth rates of the facets. Usually, the shape-controlled growth of seed crystals occurs in the presence of soluble capping agents such as polymers and surfactants, which preferentially adsorb on a specific crystal facet to facilitate growth on other facets, leading to the formation of desired shapes. This facetblocking strategy is extensively applied in the synthesis of crystals with unique shapes. Until now, the seed-mediated 
fabrication technique has been mainly performed in nonaqueous solvents at relatively high temperatures $\left(>\mathrm{ca} .80^{\circ} \mathrm{C}\right)$. The preparation of shape-controlled Pd crystals in aqueous solutions at lower temperatures is desirable for reducing cost and environmental load. In this study, Pd nanocrystals enclosed by (100) facets were prepared in an aqueous solution containing cetyltrimethylammonium bromide (CTAB) as the capping agent and ascorbic acid as the reducing agent at 30, 40 , and $50^{\circ} \mathrm{C}$ by the seed-mediated fabrication technique. In addition, the surface of the resultant Pd nanocrystals was characterized by $\mathrm{Cu}$-stripping voltammetry.

\section{Experimental}

2.1. Preparation of Pd Crystals. Reagents $\mathrm{PdCl}_{2} \cdot 2 \mathrm{NaCl} \cdot 3 \mathrm{H}_{2} \mathrm{O}$ (Wako Pure Chemical Industries, Ltd.), CTAB (Tokyo Chemical Industry Co., Ltd.), and ascorbic acid (Wako Pure Chemical Industries, Ltd.) were used as received.

First, $10 \mathrm{~mL}$ of $10 \mathrm{mM}$ CTAB aqueous solution was mixed with $2.5 \mathrm{~mL}$ of $10 \mathrm{mM} \mathrm{PdCl}_{4}{ }^{2-}$ aqueous solution, which was prepared by dissolving $\mathrm{PdCl}_{2} \cdot 2 \mathrm{NaCl} \cdot 3 \mathrm{H}_{2} \mathrm{O}$ in ultrapure water at $50^{\circ} \mathrm{C}$ in an $\mathrm{Ar}$ atmosphere. Then, $250 \mu \mathrm{L}$ of $100 \mathrm{mM}$ ascorbic acid aqueous solution was added in the mixed solution at $50^{\circ} \mathrm{C}$ in an $\mathrm{Ar}$ atmosphere, followed by stirring at the same temperature for $1 \mathrm{~h}$ to form a suspension. The suspension was centrifuged at $14800 \mathrm{rpm}$ and decanted. The black residue was washed 3 times with ultrapure water and redispersed in $0.1 \mathrm{~mL}$ of ultrapure water. The resultant suspension is denoted as Pd seed suspension.

The growth solution for shape control was prepared by mixing $20 \mathrm{~mL}$ of $50 \mathrm{mM}$ CTAB aqueous solution with $1 \mathrm{~mL}$ of $10 \mathrm{mM} \mathrm{PdCl}_{4}{ }^{2-}$ aqueous solution in a glass vial. Next, $0.1 \mathrm{~mL}$ of the Pd seed suspension was added in the growth solution at different temperatures of 30,40 , and $50^{\circ} \mathrm{C}$ in an $\mathrm{O}_{2}$ atmosphere, followed by stirring at the same temperature for $5 \mathrm{~min}$ and addition of $500 \mu \mathrm{L}$ of $100 \mathrm{mM}$ ascorbic acid aqueous solution. The resultant suspension was centrifuged at $14800 \mathrm{rpm}$ and decanted. The black residue obtained was washed 3 times with ultrapure water. After suction filtration, it was dried in vacuum at room temperature for $12 \mathrm{~h}$. The resultant $\mathrm{Pd}$ powders prepared at 30,40 , and $50^{\circ} \mathrm{C}$ are denoted as Pd-30, Pd-40, and Pd-50, respectively. For comparison, $\mathrm{Pd}$ nanoparticle-loaded carbon black $(\mathrm{Pd} / \mathrm{CB})$ was prepared by our previous method [10].

2.2. Characterization of $P d$ Crystals. The absorption spectra of the growth solution containing Pd seeds before and after addition of ascorbic acid at 30,40 , and $50^{\circ} \mathrm{C}$ were measured using a UV-Vis spectrophotometer (UV-2100PC, Shimadzu).

The crystal structures of $\mathrm{Pd}-30, \mathrm{Pd}-40$, and $\mathrm{Pd}-50$ were analyzed by X-ray diffraction (XRD; Shimadzu, XRD-6100) using a $\mathrm{Cu} \mathrm{K} \alpha$ source $(\lambda=0.1541 \mathrm{~nm}, 50 \mathrm{kV}, 30 \mathrm{~mA}$, $\left.1^{\circ} \min ^{-1}\right)$.

The mean particle sizes and shapes of the Pd seed crystals were evaluated by Cs-corrected scanning transmission electron microscopy (STEM; HD-2700, Hitachi; $200 \mathrm{kV}$ ). The $\mathrm{Pd} / \mathrm{CB}$ specimen was used to observe the Pd seeds. After the addition of CB (Ketjen Black EC300, Lion) in the $\mathrm{Pd}$ seed suspension, the mixture was sonicated for $60 \mathrm{~min}$ to prepare $\mathrm{Pd} / \mathrm{CB}$. After suction filtration, the $\mathrm{Pd} / \mathrm{CB}$ was thoroughly washed with ultrapure water. The samples for TEM microscopic measurements were obtained by dropping a dispersion of $\mathrm{Pd} / \mathrm{CB}$ catalyst in ethanol on a $\mathrm{Cu}$ microgrid (Nisshin EM Co.) with a micropipette and air-drying it. The shapes of Pd-30, Pd-40, and Pd-50 were evaluated by field emission-scanning electron microscopy (FE-SEM; Hitachi S4500). The samples for FE-SEM studies were prepared by casting a drop of each Pd dispersion onto a glassy carbon (GC) electrode.

2.3. Electrochemical Measurements of Pd Crystals. To evaluate the electrochemical properties of $\mathrm{Pd}-30, \mathrm{Pd}-40$, and $\mathrm{Pd}-50$, the dispersions of Pd-30, Pd-40, and Pd-50 were cast on a GC disk electrode $(\mathrm{Pd} / \mathrm{GC})$ with a diameter of $0.50 \mathrm{~cm}$ (geometric surface area: $0.20 \mathrm{~cm}^{2}$ ) according to the previous procedure [10]. The amount of Pd loaded on the GC disk was $20 \mu \mathrm{g} \mathrm{cm}^{-2}$. A Pt plate and a reversible hydrogen electrode (RHE) were used as the counter and the reference electrodes, respectively. The surfaces of Pd-30, Pd-40, and Pd-50 were characterized by $\mathrm{Cu}$-stripping voltammetry. The $\mathrm{Cu}$ monolayer was underpotentially deposited on the Pd crystal surfaces by holding the electrode potential at $0.3 \mathrm{~V}$ versus RHE for $3 \mathrm{~min}$ in an Ar-saturated $0.5 \mathrm{M} \mathrm{H}_{2} \mathrm{SO}_{4}$ solution containing $2 \mathrm{mM} \mathrm{CuSO}_{4}$ at $25^{\circ} \mathrm{C}$. It was then oxidized by sweeping the potential from 0.3 to $0.8 \mathrm{~V}$ versus $\mathrm{RHE}$ at a sweep rate of $10 \mathrm{mV} \mathrm{s}^{-1}$.

\section{Results and Discussion}

3.1. Morphologies of $P d-30, P d-40$, and $P d-50$. Figure 1 shows the UV-Vis absorption spectra of the growth solution containing the $\mathrm{Pd}$ seed suspension at 30,40 , and $50^{\circ} \mathrm{C}$ in an $\mathrm{O}_{2}$ atmosphere before and after the addition of ascorbic acid aqueous solution. In each case, a large absorption peak was observed between 300 and $400 \mathrm{~nm}$ before the addition of ascorbic acid aqueous solution. This peak is assigned to metal-centered transition of $\mathrm{PdCl}_{4}{ }^{2-}[11,12]$. After the addition of ascorbic acid aqueous solution, the absorbance of the peak decreased with an increase in the reaction time regardless of the reaction temperature, suggesting that $\mathrm{PdCl}_{4}{ }^{2-}$ was used for Pd deposition. As can be seen from Figure 1, the time required for the disappearance of the absorption peak is shorter at higher temperatures, which is due to the increase in the reduction rate of $\mathrm{PdCl}_{4}{ }^{2-}$ to $\mathrm{Pd}$. The absorption peak completely disappeared within $24 \mathrm{~h}$ at $30^{\circ} \mathrm{C}$, because of the slow reduction rate of $\mathrm{PdCl}_{4}{ }^{2-}$ to $\mathrm{Pd}$ at this temperature. At $50^{\circ} \mathrm{C}$, the absorption peak completely disappeared within $1 \mathrm{~h}$.

Figure 2 shows the XRD patterns of $\mathrm{Pd}-30, \mathrm{Pd}-40$, and Pd-50. In each XRD pattern, three diffraction peaks were observed at $2 \theta=40.1,46.7$, and $68.1^{\circ}$, which are assigned to (111), (200), and (220) planes of face-centered cubic Pd, respectively; this suggests the formation of metallic $\mathrm{Pd}$. The ratio of peak intensity of the (200) plane to that of the (111) plane for all the samples (Pd-30, Pd-40, and Pd-50) was 0.35, whereas for the $\mathrm{Pd} / \mathrm{CB}[10]$, in which the $\mathrm{Pd}$ nanoparticles were spherical, it was 0.22 . This suggests that $\mathrm{Pd}-30, \mathrm{Pd}-40$, 


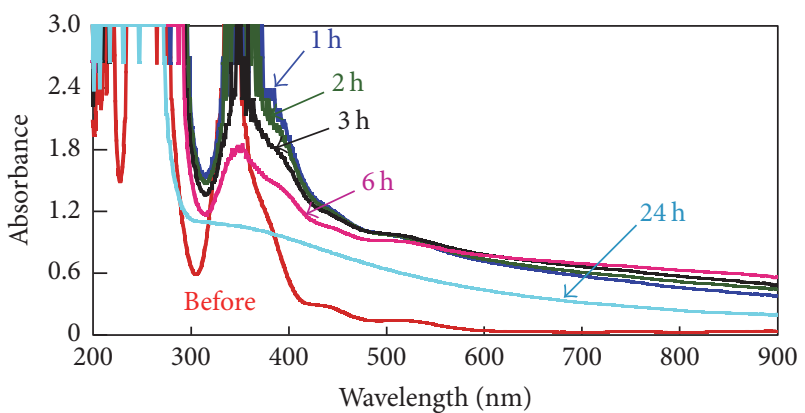

(a)

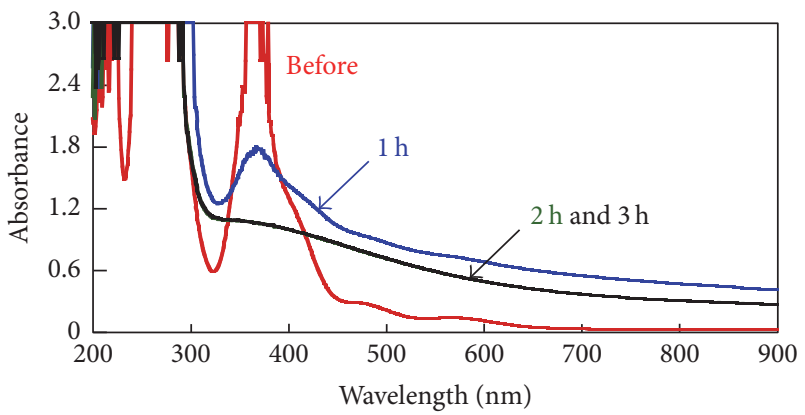

(b)

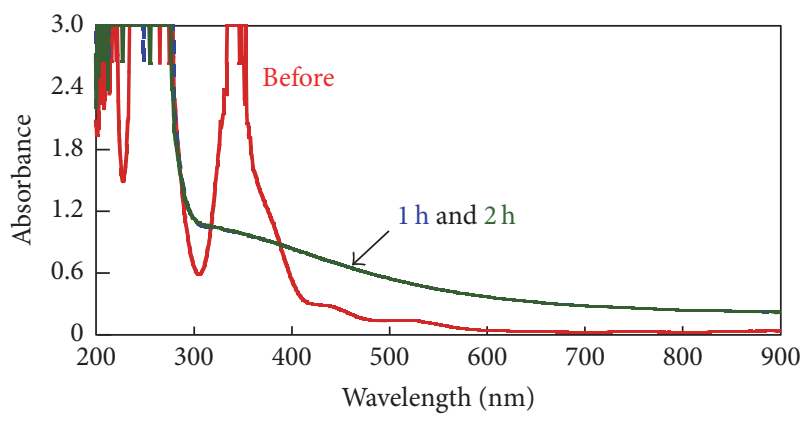

(c)

FIGURE 1: UV-Vis absorption spectra of growth solution containing Pd seeds before and after addition of ascorbic acid at (a) $30^{\circ} \mathrm{C}$, (b) $40^{\circ} \mathrm{C}$, and (c) $50^{\circ} \mathrm{C}$ under $\mathrm{O}_{2}$ atmosphere.

and $\mathrm{Pd}-50$ have a higher proportion of $\mathrm{Pd}(100)$ planes than $\mathrm{Pd} / \mathrm{CB}$.

We investigated the shapes of the Pd seeds by TEM and those of Pd-30, Pd-40, and Pd-50 by SEM; the results are shown in Figure 3. Pd nanocrystals with different shapes, such as rectangular bar, cube, truncated polyhedron, and truncated cube, are observed in each image. For each sample, the shapes of more than $200 \mathrm{Pd}$ crystals chosen randomly from several SEM images were examined and classified into two categories: Pd crystals enclosed by only (100) facets and others; and the results are summarized in Table 1. The size of the Pd seed was ca. $8 \mathrm{~nm}$. The size of the Pd crystals increased when the Pd seed suspension was added in the growth solution.

It is known that $\mathrm{Br}^{-}$ions preferentially adsorb on the $\operatorname{Pd}(100)$ facet [13], causing preferential deposition of Pd on other facets. In the present growth solution, $\mathrm{Br}^{-}$in $\mathrm{CTAB}$ will
TABLE 1: Shape distribution profiles for Pd-30, Pd-40, and Pd-50.

\begin{tabular}{lcc}
\hline Pd crystal & Crystals enclosed by $(100) / \%$ & Others $/ \%$ \\
\hline Pd-30 & 51 & 49 \\
Pd-40 & 25 & 75 \\
Pd-50 & 28 & 72 \\
\hline
\end{tabular}
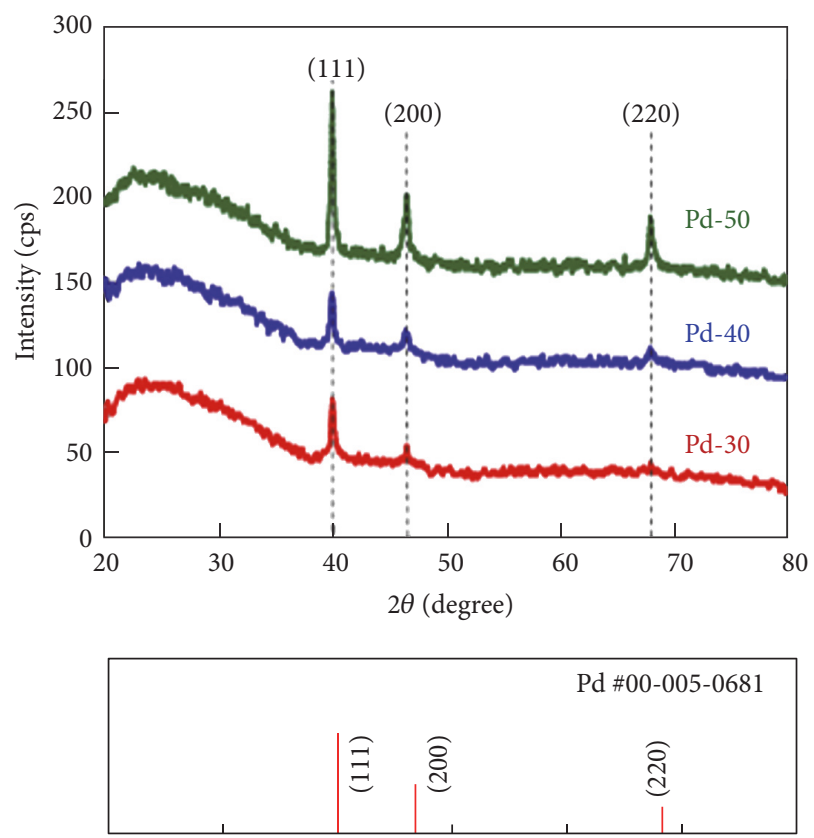

Figure 2: XRD patterns of Pd-30, Pd-40, and Pd-50.

preferentially adsorb on the (100) facet of the Pd seeds and inhibit the deposition of Pd, leading to Pd crystals enclosed by the (100) facets [13]. Therefore, the adsorbed $\mathrm{Br}^{-}$has to inactivate the (100) facet of this crystal to continue the growth of (111) facet.

Xiong et al. have extensively explored the method of oxidative etching for shape-controlled synthesis of metal nanostructures [8]. Oxidative etching, caused by oxygen and chloride, can be used to remove $\mathrm{Br}^{-}$ions from the (100) facet and thus expose sites for addition of Pd atoms. At a sufficiently high concentration, the $\mathrm{Br}^{-}$ions would make it difficult to perform oxidative etching over the facet. However, with the assistance of water, oxidative etching can occur locally on a specific facet of cubic Pd [8]. When sufficient Pd atoms exist on the etched sites, deposition of Pd atoms will be faster than the dissolution of Pd atoms caused by etching. It has been reported that preferential growth at active sites breaks the cubic symmetry of a Pd nanocrystal and leads to the formation of Pd nanorods and nanobars [8]. In the present study, $\mathrm{O}_{2}$ and $\mathrm{Cl}^{-}$(from $\mathrm{PdCl}_{4}{ }^{2-}$ ) were included in the growth solution. Thus, according to Figure 3, the Pd crystals enclosed by only (100) facets exhibit not only cubic but also anisotropic shapes such as rectangular bars.

The proportion of Pd crystals enclosed by only the (100) facets in Pd-30 was higher than that in Pd-40 and Pd50 , suggesting that the reaction temperature influences [2] the formation of Pd crystals enclosed by only the (100) 


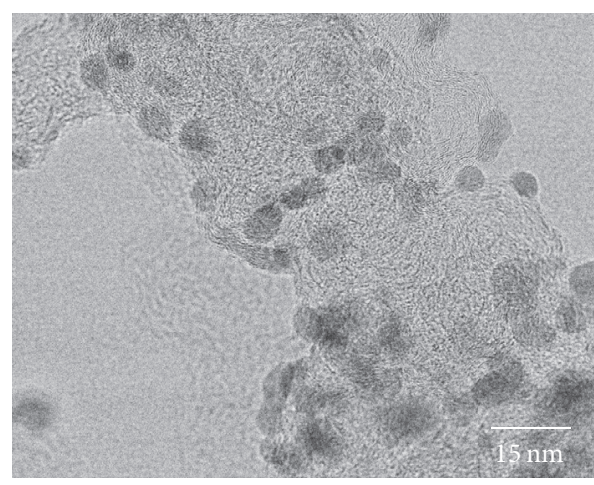

(a) Pd seed

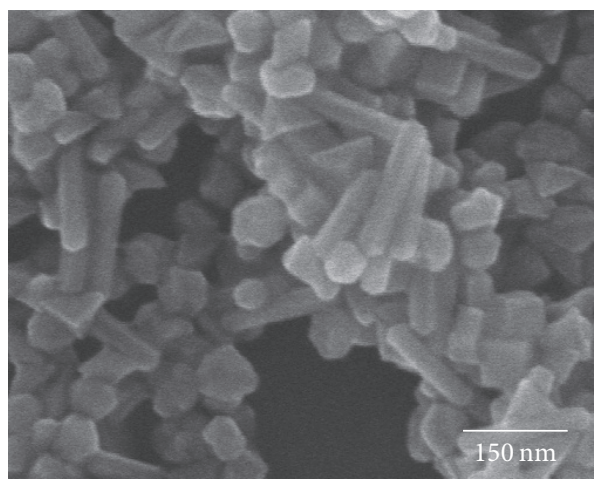

(c) $\mathrm{Pd}-40$

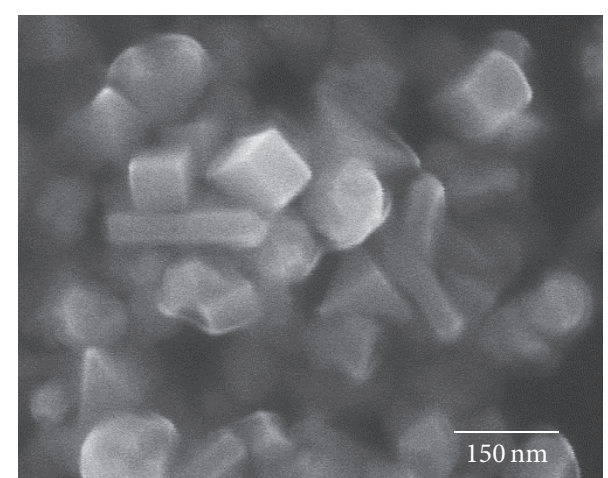

(b) Pd-30

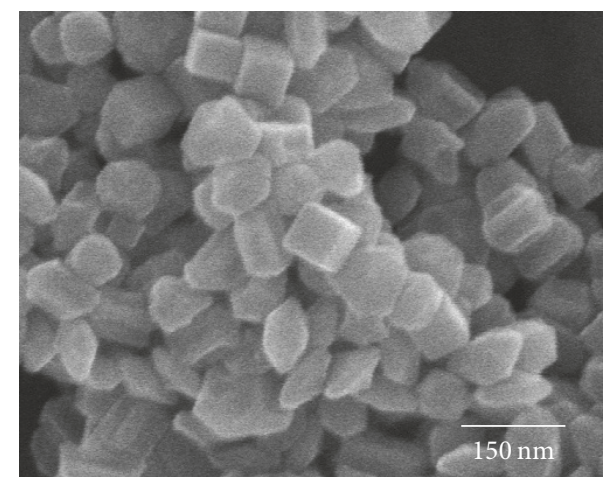

(d) Pd-50

FIgURE 3: TEM image of Pd seed and SEM images of Pd-30, Pd-40, and Pd-50.

facets. The change in the temperature can exponentially influence the reaction rate, which includes dissolution and deposition rates in the present case. When the adsorption energy of $\mathrm{Br}^{-}$in the growth solution is strengthened at low temperatures, the deposition and the dissolution of Pd do not occur easily. On the contrary, the dissolution and the deposition rates are faster at higher temperatures, and the crystal shape changes via cycles of dissolution and reduction. In addition, when the concentration of the Pd precursor is sufficiently high, Pd deposition will be faster than Pd dissolution [8]. The concentration of the Pd precursor in the present growth solution appears to satisfy the condition at which the deposition rate is higher than the dissolution rate at low temperatures.

3.2. Cu-Stripping Voltammograms of $P d-30, P d-40$, and $P d-50$. The surfaces of Pd-30, Pd-40, and Pd-50 were characterized by $\mathrm{Cu}$-stripping voltammetry in an Ar-saturated $(0.5 \mathrm{M}$ $\mathrm{H}_{2} \mathrm{SO}_{4}+2 \mathrm{mM} \mathrm{CuSO}_{4}$ ) aqueous solution. Figure 4 shows the $\mathrm{Cu}$-stripping voltammograms from 0.3 to $0.8 \mathrm{~V}$ versus RHE for Pd-30, Pd-40, and Pd-50 and Pd/CB for reference. The stripping peaks of the underpotentially deposited $\mathrm{Cu}$ monolayer are sensitive to crystallographic orientations of the surface Pd atoms [14-16]. Cuesta et al. found that the stripping peaks of $\mathrm{Cu}$ adatoms on the $\mathrm{Pd}(111)$ and the $\mathrm{Pd}(100)$ single crystals are observed at approximately 0.49 and $0.54 \mathrm{~V}$ versus RHE, respectively, whereas on $\mathrm{Pd}(110)$, the two stripping peaks are observed at approximately 0.37 and $0.53 \mathrm{~V}$ versus
RHE. In the Cu-stripping voltammogram of $\mathrm{Pd} / \mathrm{CB}$, a large $\mathrm{Cu}$-stripping peak $(30 \mu \mathrm{A})$ corresponding to $\mathrm{Pd}(111)$ and a small peak $(6.3 \mu \mathrm{A})$ corresponding to $\mathrm{Pd}(110)$ are observed, but the peak corresponding to $\mathrm{Pd}(100)$ is not observed. On the other hand, $\mathrm{Cu}$-stripping peaks corresponding to $\mathrm{Pd}(110)$, (111), and (100) are observed at approximately $0.36,0.48$, and $0.54 \mathrm{~V}$ versus RHE, respectively, in Pd-30, Pd-40, and Pd-50, suggesting that all the Pd surfaces had these facets. As shown in Figure 4, the $\mathrm{Cu}$-stripping currents at $0.36 \mathrm{~V}$ for all the samples (Pd-30, Pd-40, and Pd-50) are similar. The ratios of the peak current at 0.54 and $0.48 \mathrm{~V}$ were $0.60,0.54$, and 0.47 for Pd-30, Pd-40, and Pd-50, respectively, suggesting that the proportion of the (100) facet on the Pd surface was higher at lower temperatures.

\section{Conclusions}

Pd crystals enclosed by (100) facets were synthesized by the seed-mediated fabrication technique at 30,40 , and $50^{\circ} \mathrm{C}$. Before the addition of ascorbic acid aqueous solution, a large absorption peak corresponding to metal-centered transition of $\mathrm{PdCl}_{4}{ }^{2-}$ was observed between 300 and $400 \mathrm{~nm}$. After the addition of ascorbic acid aqueous solution, the absorbance of the peak decreased with an increase in the reaction time, suggesting that $\mathrm{PdCl}_{4}{ }^{2-}$ was used for the Pd deposition. From the XRD studies, the ratios of the peak intensity of (111) and (200) planes for Pd-30, Pd-40, and Pd-50 were higher than that of spherical Pd/CB. The SEM results showed that 


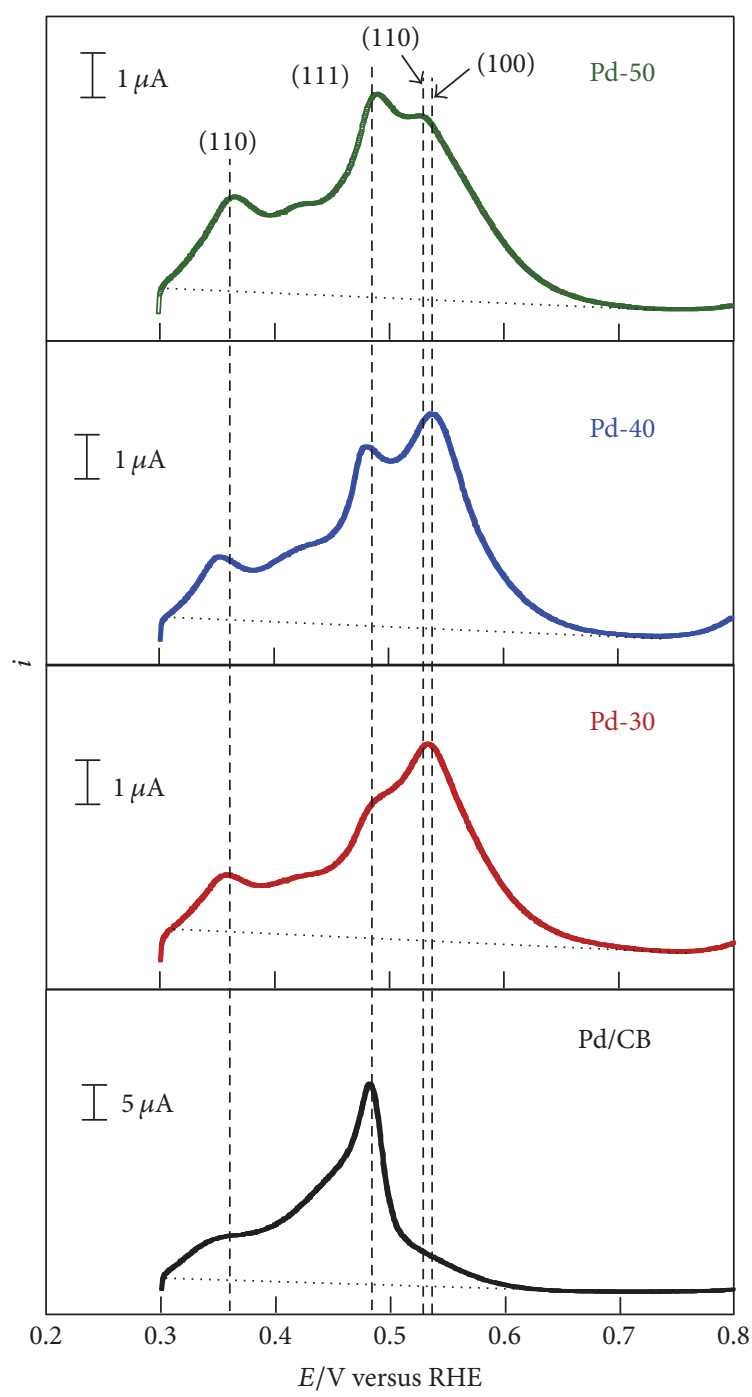

FIGURE 4: Cu-stripping voltammograms for Pd-30, Pd-40, and Pd50 in an Ar-saturated $\left(0.5 \mathrm{M} \mathrm{H}_{2} \mathrm{SO}_{4}+2 \mathrm{mM} \mathrm{CuSO}_{4}\right)$ aqueous solution.

the proportion of Pd crystals enclosed by only the (100) facets increased with a decrease in the temperature. The $\mathrm{Cu}-$ stripping currents at $0.36 \mathrm{~V}$ for Pd-30, Pd-40, and Pd-50 were similar, whereas the ratio of the peak current at 0.54 and $0.48 \mathrm{~V}$ increased with a decrease in the temperature, suggesting that the proportion of Pd crystals enclosed by (100) was higher at lower temperatures.

\section{Conflicts of Interest}

The authors declare that they have no conflicts of interest regarding the publication of this paper.

\section{References}

[1] N. Hoshi, M. Nakamura, and S. Kondo, "Oxygen reduction reaction on the low index planes of palladium electrodes modified with a monolayer of platinum film," Electrochemistry Communications, vol. 11, no. 12, pp. 2282-2284, 2009.
[2] X. Huang, H. Zhang, C. Guo, Z. Zhou, and N. Zheng, "Simplifying the creation of hollow metallic nanostructures: Onepot synthesis of hollow palladium/platinum single-crystalline nanocubes," Angewandte Chemie International Edition, vol. 48, no. 26, pp. 4808-4812, 2009.

[3] Y.-H. Chen, H.-H. Hung, and M. H. Huang, "Seed-mediated synthesis of palladium nanorods and branched nanocrystals and their use as recyclable suzuki coupling reaction catalysts," Journal of the American Chemical Society, vol. 131, no. 25, pp. 9114-9121, 2009.

[4] N. Naresh, F. G. S. Wasim, B. P. Ladewig, and M. Neergat, "Removal of surfactant and capping agent from Pd nanocubes (Pd-NCs) using tert-butylamine: its effect on electrochemical characteristics," Journal of Materials Chemistry A, vol. 1, no. 30, pp. 8553-8559, 2013.

[5] M. Liu, Y. Zheng, L. Zhang, L. Guo, and Y. Xia, “Transformation of Pd nanocubes into octahedra with controlled sizes by maneuvering the rates of etching and regrowth," Journal of the American Chemical Society, vol. 135, no. 32, pp. 11752-11755, 2013.

[6] K. Gong, M. B. Vukmirovic, C. Ma, Y. Zhu, and R. R. Adzic, "Synthesis and catalytic activity of Pt monolayer on Pd tetrahedral nanocrystals with CO-adsorption-induced removal of surfactants," Journal of Electroanalytical Chemistry, vol. 662, no. 1, pp. 213-218, 2011.

[7] M. Chen, B. Wu, J. Yang, and N. Zheng, "Small adsorbateassisted shape control of Pd and Pt nanocrystals," Advanced Materials, vol. 24, no. 7, pp. 862-879, 2012.

[8] Y. Xiong, H. Cai, B. J. Wiley, J. Wang, M. J. Kim, and Y. Xia, "Synthesis and mechanistic study of palladium nanobars and nanorods," Journal of the American Chemical Society, vol. 129, no. 12, pp. 3665-3675, 2007.

[9] B. Lim, Y. Xiong, and Y. Xia, "A water-based synthesis of octahedral, decahedral, and icosahedral Pd nanocrystals," Angewandte Chemie International Edition, vol. 46, no. 48, pp. 9279-9282, 2007.

[10] H. Inoue, R. Sakai, T. Kuwahara, M. Chiku, and E. Higuchi, "Simple preparation of $\mathrm{Pd}$ core nanoparticles for $\mathrm{Pd}$ core/Pt shell catalyst and evaluation of activity and durability for oxygen reduction reaction," Journal of Catalysis, vol. 5, no. 3, pp. 13751387, 2015.

[11] Z. Yang, A. B. Smetana, C. M. Sorensen, and K. J. Klabunde, "Synthesis and characterization of a new tiara Pd(II) thiolate complex, $\left[\mathrm{Pd}\left(\mathrm{SC}_{12} \mathrm{H}_{25}\right)_{2}\right]_{6}$, and its solution-phase thermolysis to prepare nearly monodisperse palladium sulfide nanoparticles," Inorganic Chemistry, vol. 46, no. 7, pp. 2427-2431, 2007.

[12] V. L. Nguyen, M. Ohtaki, T. Matsubara, M. T. Cao, and M. Nogami, "New experimental evidences of Pt-Pd bimetallic nanoparticles with core-shell configuration and highly fineordered nanostructures by high-resolution electron transmission microscopy," The Journal of Physical Chemistry C, vol. 116, no. 22, pp. 12265-12274, 2012.

[13] W. Annan, P. Qing, and L. Yadong, "Rod-shaped Au-Pd coreshell nanostructures," Chemistry of Materials, vol. 23, no. 13, pp. 3217-3222, 2011.

[14] J. Zhang, M. B. Vukmirovic, Y. Xu, M. Mavrikakis, and R. R. Adzic, "Controlling the catalytic activity of platinummonolayer electrocatalysts for oxygen reduction with different substrates," Angewandte Chemie International Edition, vol. 44, no. 14, pp. 2132-2135, 2005.

[15] Z. D. Wei, Y. C. Feng, L. Li et al., "Electrochemically synthesized $\mathrm{Cu} / \mathrm{Pt}$ core-shell catalysts on a porous carbon electrode for 
polymer electrolyte membrane fuel cells," Journal of Power Sources, vol. 180, no. 1, pp. 84-91, 2008.

[16] A. Cuesta, L. A. Kibler, and D. M. Kolb, "Method to prepare single crystal electrodes of reactive metals: application to Pd(hkl)," Journal of Electroanalytical Chemistry, vol. 466, no. 2, pp. 165-168, 1999. 

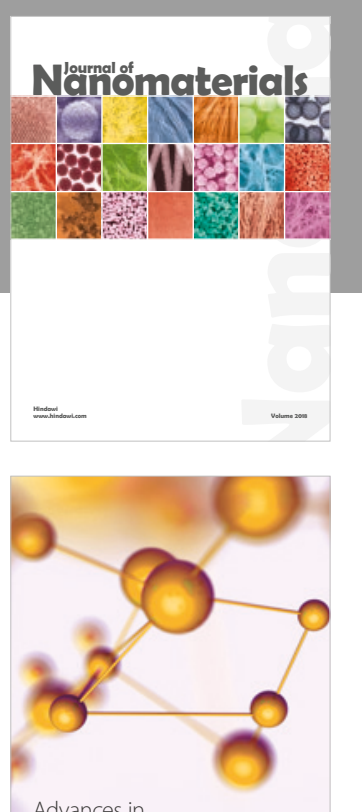

Physical Chemistry
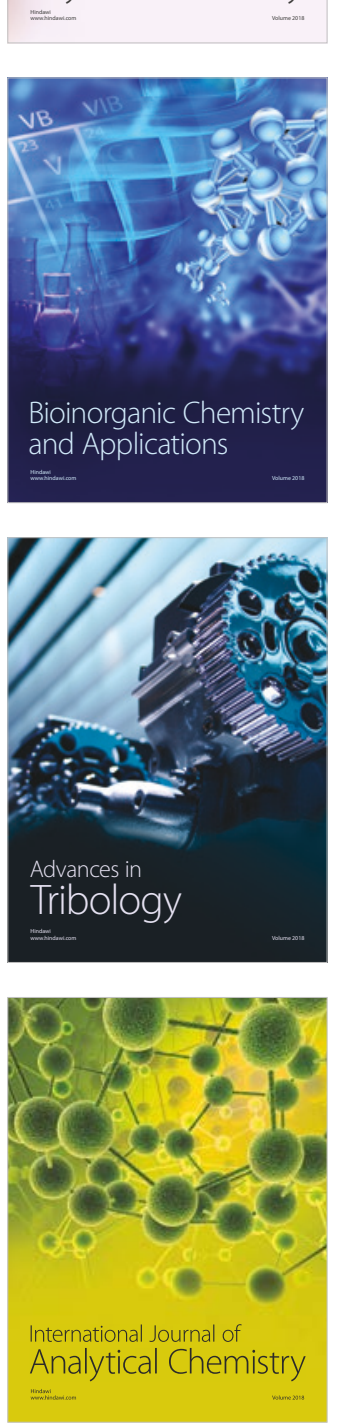

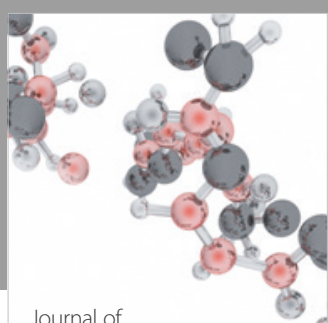

Analytical Methods

in Chemistry

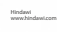

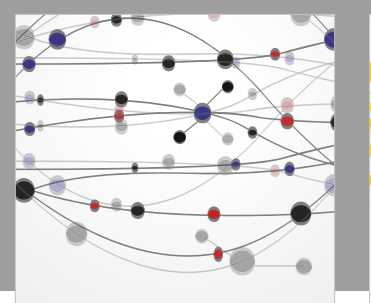

The Scientific World Journal

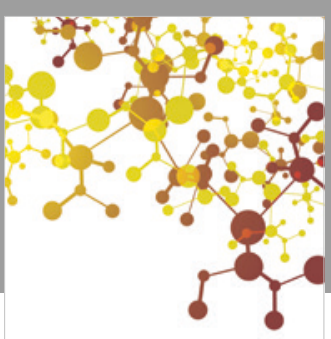

Journal of

Applied Chemistry
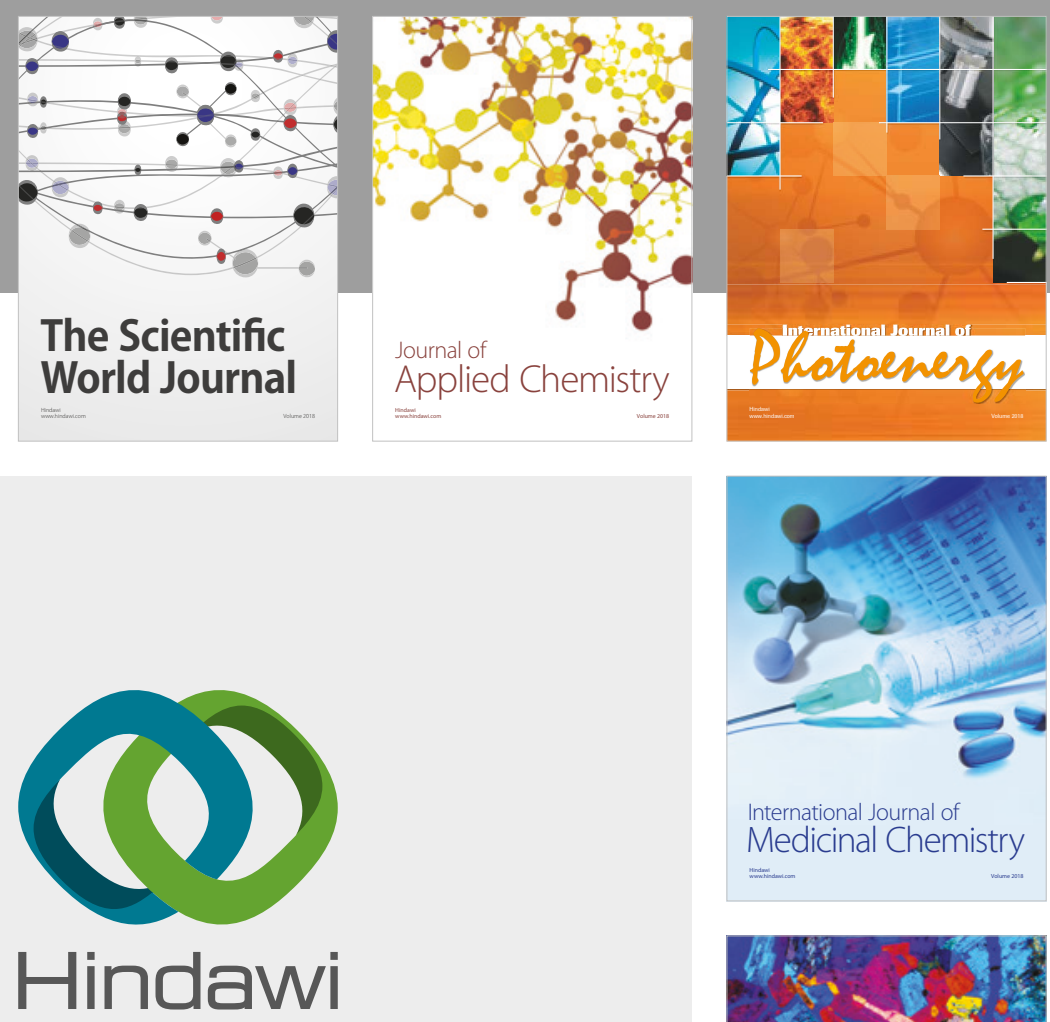

Submit your manuscripts at

www.hindawi.com
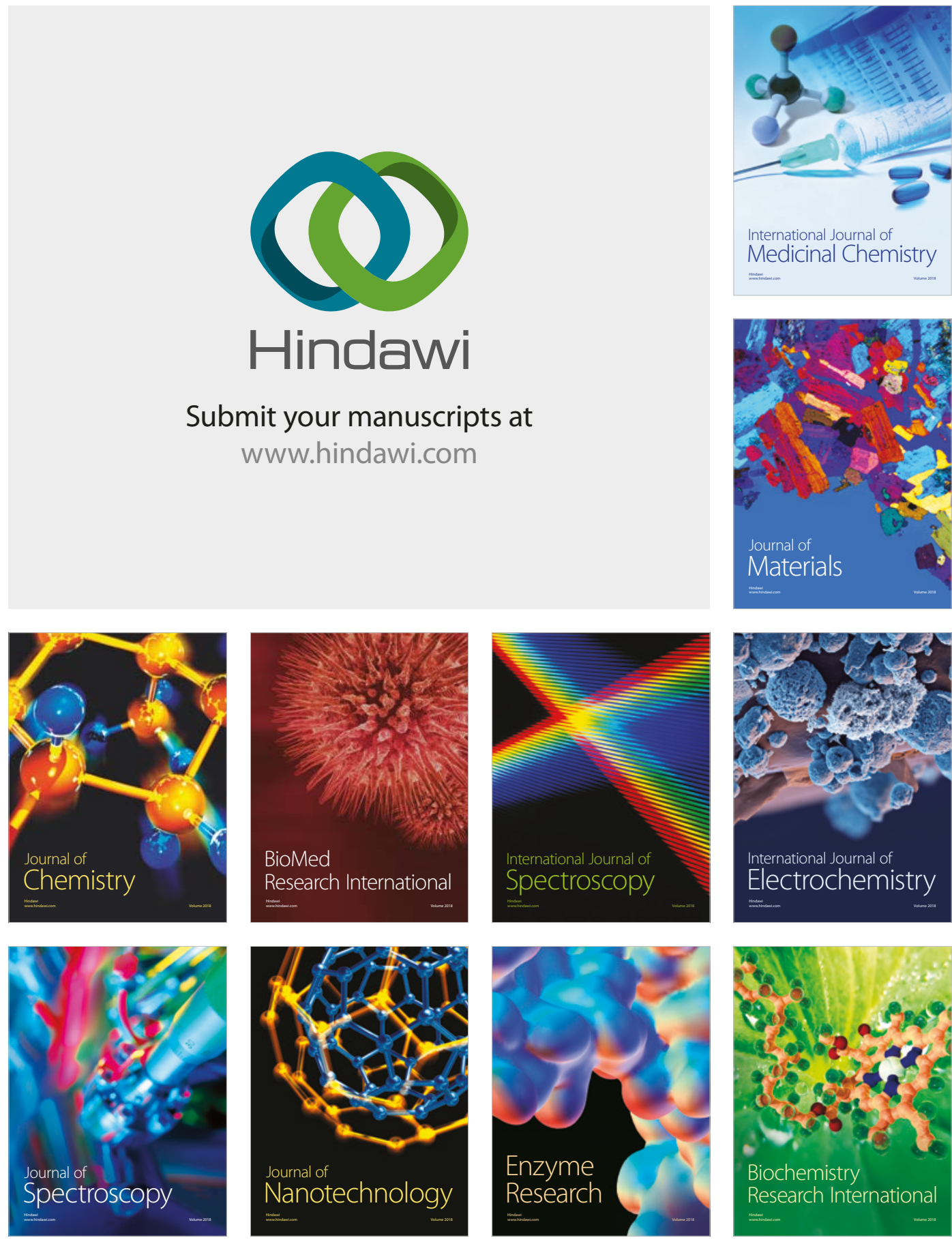
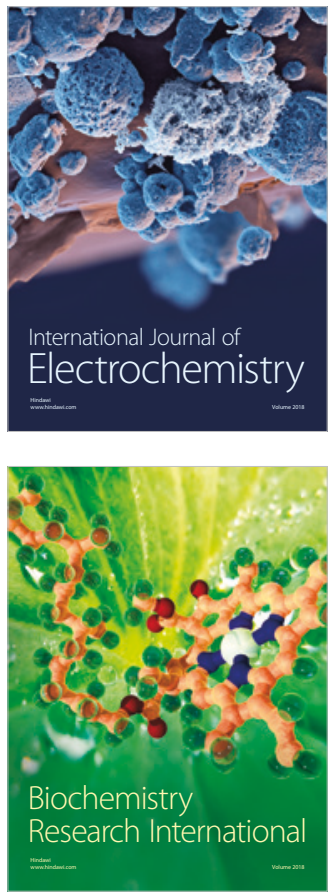